\title{
Polyhydroxybutyrate as Bio-Degradable Plastic - A Review
}

\author{
Shivalkar Yadav K*. Prabha R. \\ *Ph.D Scholar, Department Of Dairy Microbiology, Dairy science College, Kvafsu, Hebbal, Bengaluru-560024
}

\begin{abstract}
Plastic is one of the major source of pollutants at present time in the world, regularly used for packaging materials, carry bags, manufacturing of different types of materials etc. So, to reduce the increasing environmental pollution from synthetic plastic an alternative must be developed. This need can be fulfilled by use of bioplastics. Polyhydroxyalkanoates are polymers produced by bacteria among which Polyhydroxybutyrate (PHB) is one major group. Bacterial polyesters have attracted much attention as biodegradable biocompatible polymers. Poly-3-hydroxybutyrate, a microbial produced thermoplastic and gained major importance due to their structural diversity and close analogy to plastics. These are gaining more and more importance world over. Different sources (natural isolates, recombinant bacteria, plants) and other methods are being investigated to exert more control over the quality, quantity and economics of poly(3-hydroxybutyrate) (PHB) production. Some bacterial species like Bacillus spp., Pseudomonas spp., Aeromonas spp., Cupriavidus spp. have been extensively used for industrial production of PHB. The aim of writing this review is to help to take up research work on such PHB producing bacteria for bio-plastic and to replace the use of synthetic plastic.
\end{abstract}

Keywords: Bioplastics, PHB, Synthetic plastic, Bacteria.

\section{Introduction}

Of all pollutants, plastic is one of the major pollutant now-a-days causing environmental pollution around the world. An alternative to be developed for replacing this non bio-degradable pollutant, which became part and parcel of everyone daily life for packing, carrying vegetables and for many other purposes. Biodegradable plastic has been developed many years back but still some modification is required for large scale production in industries so that it can replace the plastic of petroleum origin. An environment friendly biodegradable material is poly-3-hydroxybutyrate (PHB) which and can be produced from renewable resources. PHB, whose physical properties are similar to polypropylene, has attracted industrial attention as an environmentally degradable plastic for a wide range of agricultural, marine and medical applications. Since the production of bio-plastic is expensive many techniques have been adopted for large scale production. Selection of proper strains of bacteria, which are capable of producing or accumulating PHB in large scale, is the major criteria.

\section{Environmental Pollution Causes Hazardous To Life}

Pollution is a condition in which hazardous contaminants are introduced in to the natural environments leading to adverse changes in the environment and mainly by human activity is the major cause for the same. Pollutants or contaminants are the components that cause pollution and this may be foreign chemicals, substances or different forms of energy like heat, noise etc. Pollution may be point source or non-point source. The point source pollution is the type where pollution occurs in the same site where the pollutants are produced where as non-point source pollution is different from this type where the pollutants are carried to a different place from its origin via different transport media. Pollution may arise in different geographical locations leading to deformations in soil, water or air. Among different types pollutions one of the major type is marine pollution, caused by various transport vehicles such as ship, steamers, submarines etc. and causes entry of agricultural, industrial wastes into ocean water. Water from river and other water bodies flow and meet in the ocean. This carries various waste materials which are harmful for the marine organisms and cause their death.

Pollutions cause critical problems to the global geochemical cycles as well as the sustainable habitation of humans as well as other living organisms. Other organisms which are suffer from the adverse effects of natural changes, the main culprit is human. Various types of hazardous substances can enter the natural environment by a number of natural and/or anthropogenic activities, disturbing the living systems along with many adverse changes in the environment (1). In different urban areas huge megaplexes have been constructed which are not sustainable and they experience problems with waste management, heat islands, increasing pollution and crowding of increasing population etc. (2). $\mathrm{CO}_{2}$ is toxic for pregnant women and when exposed, the fetus may be harmed. Likewise, car exhaust gases damage health of both adults and children, leading to change in behaviour and psycho-social development of children (3). 


\section{Traditional Approach For Bio-Degradable Plastic}

Bio-plastics are biodegradable plastics with similar properties of synthetic plastics. And biodegradation can be defined as a chemical process during which micro-organisms present in the environment convert materials into natural substances such as water, carbon dioxide, and compost. Synthetic plastics remain in the environment for long time as they are resistant to degradation (4). Bioplastics are made from variety of sources like polysaccharides, lipids and also proteins (5). A few examples of protein used as substrates for bioplastic production are soy protein, wheat gluten, zein, rice and egg albumin. Plasticizer, which is a rupturing agent added with proteins to increase plasticity (6).

The petroleum based conventional plastics are non-renewable where the feed stocks are reinforced by carbon fibres (7). Renewable resource feed stocks of plastics include polymers derived from microbial culture reinforced with natural fibres such as cellulose, jute etc. (8). The major cause of pollution is accumulation of synthetic and petroleum based plastics in the environment. The novel approach to produce plastic, which is an essential polymer used in our day to day life, using microbes. It helps in reducing the environmental pollution as well as the consumption of petroleum to make plastic bags. So it can be called with single word as bio-plastic which is environment friendly.

\section{The History of Bioplastic Production}

In 1926, Lemoigne from the Pasteur Institute, France first detected Poly-3-hydroxybutyrate (9). Poly3hydroxybutyrate (PHB) is produced by joining of $\beta$ - Hydroxybutyrate monomers by ester bonds. Different microbial species present in the environment able to produce approximately 100 PHAs have been identified . Until 1980s, scientists were not able to find out any alternative for petroleum based plastics to reduce the pollution. In 80s, Anthony Sinskey and his colleagues successfully isolated the first enzyme 'thiolase' from Massachusetts Institute of Technology (MIT) and which plays a major role in the biological process to produce bioplastics followed by the discovery of the genes required for the synthesis. In 1987, the first patent applications of bioplastics were made and accepted in1993.

\section{Microbes As The Bioplastic Producers}

Microbes have been reported to be the potent producers of PHB due to their high adaptability in various extreme environmental conditions. Out of these, Bacillus spp., Pseudomonas spp. and Vibrio spp. are found to be more efficient for PHB production due to their higher stability and reproducibility under environmental stress.

\section{Efficient Microbes As Bioplastic Producers}

Many types of bacteria, such as Bacillus spp., Pseudomonas spp., Cupriavidus spp., and Aeromonas spp., have been studied for their use in industry for efficient capacity to produce PHA (10). Bacterial species like Bacillus megaterium, Ralstonia eutropha gained much more attention from the researchers. The PHB production from Bacillus megaterium has been reported to be around $84 \%$ (11). Marine bacteria have recently attracted attention as potentially useful candidates for the production of PHAs.. The main advantage of biodegradable polymers is that anaerobic microbes completely degraded to water, carbon dioxide and methane in various environments such as soil, sea, lake water and sewage and so it is disposable without harm to the environment (12).Although a few kinds of marine bacteria have been investigated for PHA production under some marine conditions, characterization have not been done in details of the resultant PHAs Haloferax, Haloarcula, Natrialba, Haloterrigena, Halococcus, Haloquadratum, Halorubrum, Natronobacterium, Natronococcus and Halobacterium some Haloarchaeal species have found to be efficient producer of PHB(13).Bacterial genera like Beneckea and Vibrio have been found to be first reported potent producers of PHA isolated from marine sediments (14).

\section{Discussion}

Plastic is one of the major sources of pollutants causing environmental pollution. An alternative non bio-degradable pollutant must be developed to replace because everyone in daily life for packing, carrying vegetables and for many other purposes they are used. Production and extraction of Bio-degradable plastic has been developed still some modification is required for large scale production in industries so that it can replace the petroleum origin. Since the production of bio-plastic is expensive many techniques have been adopted for large scale production. But, proper selection of strains of bacteria, which are capable of producing or accumulating PHB in large scale. 


\section{Conclusion}

In the 21st century we are living with heavy load of pollutions from different sources including polythene wastes, hence there is requirement of suitable, economical, harmless alternative which is of huge demand. Bioplastics are the most suitable remedy for this environmental pollution through plastic of the petroleum origin.

\section{Conflict of interest:}

No Conflict of Interest declared

\section{References}

[1]. Kampa M. and Castanas E . Human Health Effects of Air Pollution. Environmental Pollution. 151, $2008,362-367$.

[2]. William J.M. Urban environment: Defining its nature and problems and developing strategies to overcome obstacles to sustainability and quality of life. Environmental Pollution. 159, 2011, 1963-1964.

[3]. Markert B., Wuenschmann S., Fraenzle S., Figueiredo A.M.G., Ribeiro A.P., Wang M . Bioindication of atmospheric trace metals With special references to megacities. Environmental Pollution. 159, 2011,1991-1995.

[4]. Aminabhavi T.M., Balundgi R.H., Cassidy P.E . Review on biodegradable plastics. Composite Materials. 7(5-6), 1990, 421-432.

[5]. Gonzalez-Garcia Y., Nungaray J., Cordova J., Gonzalez-Reinoso O., Koller M., Atlic A., Braunegg G . Biosynthesis and characterization of polyhydroxyalkanoates in the polysaccharide-degrading marine bacterium Saccharophagus degradans ATCC 43961. Journal of Indian Microbiology and Biotechnology. 35, 2008, 629-633.

[6]. Pommet M., Redl A., Guilbert S., Morel M.H . Intrinsic influence of various plasticizers on functional properties and reactivity of wheat gluten thermoplastic materials. Journal of Cereal Science. 42, 2005, 81-91.

[7]. Williams G., Pool R. Composites from natural fibers and soy oil resins. Applied Polymer Plastics Technology and

[8]. Engineering. 29(3), 2000, 235-262.

[9]. Bismarck A., Aranberri-Askargorta I., Springer J., LampkeT., Wielage B., SamboulisA., Shenderovick I., Limbach H . Surface characterization of flax, hemp, and cellulose fibers; Surface properties and the water uptake behavior. Polymer Composites. 23(5), 2002, 872-894.

[10]. Schubert P., Steinbuchel A., Schlegel H.G . Cloning of the Alcaligenes eutrophus Genes for Synthesis of Poly-3-Hydroxybutyric Acid (PHB) and Synthesis of PHB in Escherichia coli. Journal of Bacteriology. 170(12), 1988.5837-5847.

[11]. Fuchtenbusch B., Wulbrandt D., Steinbuchel A. Production of polyhydroxyalkanoic acids by Ralstonia eutropha and Pseudomonas oleovorans from oil remaining from Biotechnological rhamnose production. Applied Microbiology and Biotechnology. 53, 2000,167-172.

[12]. Prasanna T., Ajay Babu P., Dhanavara L.,Chakrapani R., Ramachandra Rao C.S.V. Production of Poly (3-hydroxybutyrate) by Bacillus species isolated from soil. Journal of Pharma Research \& Reviews.1, 2011, 15-18.

[13]. Brandl H., Gross R.A., Lenz R.W., Fuller R.C . Pseudomonas oleovorans as a source of poly ( $\beta$-hydroxyalkanoates) for potential application as biodegrdadable polysters. Applied Environmental Microbiology. 54, 1988, 1977-1982.

[14]. Poli N., Donato P.D., Abbamondi G.R., Nicolaus B .Synthesis, Production, and Biotechnological Applications of Exopolysaccharides and Polyhydroxyalkanoates by Archaea. Archaea. 2011,693253.

[15]. Lopez-Cortes A., Lanz-LandazuriA.,Garcia-Maldonado J.Q. Screening and Isolation of PHB-Producing Bacteria in a Polluted Marine Microbial Mat. Microbial Ecology. 56, 2008, 112-120. 